\title{
Identifying Enablers of E-Manufacturing
}

\author{
Rajeev Saha and Sandeep Grover \\ Department of Mechanical Engineering, YMCA University of Science and Technology, Sector-6, Faridabad 121006, Haryana, India
}

Correspondence should be addressed to Rajeev Saha, rajeevsaha@gmail.com

Received 31 January 2011; Accepted 28 March 2011

Academic Editors: K. Ghali and Y. He

Copyright ( 12011 R. Saha and S. Grover. This is an open access article distributed under the Creative Commons Attribution License, which permits unrestricted use, distribution, and reproduction in any medium, provided the original work is properly cited.

\begin{abstract}
The term e-manufacturing refers to the ability of a manufacturing system to integrate various inputs using internet and intranet. With the market being increasingly competitive and customer oriented desiring to get best of the quality at cheapest available price of a product in shortest possible time, the role of e-manufacturing is pivotal towards the success of a company. Another important fact is that each customer may desire to have a certain different set of values added to the product being purchased. Customers want to voice their concerns directly to manufacturers thereby necessitating an interface to hear them in real-time and take suitable action thereupon, if needed, in real-time. As such identifying the enablers of e-manufacturing has become important for manufacturer in customer-oriented manufacturing to lure new customers along with retaining the old customers. It will also result in closing the gap between demand and supply of a product. This paper tries to assimilate the key enablers of e-manufacturing.
\end{abstract}

\section{Introduction}

Strictly speaking, the shop floor has always been viewed in isolation in a traditional manufacturing system. The factory operated as an autonomous unit, with its own set of goals and parameters. While this is a simple model for managing a factory, it is also inefficient and inflexible. Leaving the production department to its own devices means it is financially unaccountable at a time when stakeholders are demanding increased returns on net assets.

While traditionally manufacturing industry was product centric in nature, it is now slowly moving towards being customer centric. It has become imminently clear that making the customer the heart of the business process is essential. Relying on their products to increase profitability is no longer the answer. Customer focus is the buzzword in the manufacturing industry and the pivotal point in the business process. Manufacturers are fast accepting the fact that in order to boost sales and increase profits they need to pay more attention to customer satisfaction. Advanced Manufacturing Technology (AMT) was the next step towards being customer centric.

Though Advanced Manufacturing Technology (AMT) was thought as sufficient for customer driven market ap- proach, success was only partial in today's internet-driven economy, that is, respond to customer demand in real-time. A real time response to the customer specific demand can only be met by integrating AMT with internet to form an integral part of e-business. This was the philosophy behind e-manufacturing.

E-manufacturing encompasses different meaning to different set of people. Just like "quality" has different definitions as perceived by different set of people, the same is the case with e-manufacturing. One of the popular definitions is by AMR Research [1]:

"The core of a manufacturing strategy is the technology roadmap for information transparency between the customer, manufacturing operations, and suppliers. An e-manufacturing strategy takes e-business processes, such as build to order and reliability-centered maintenance, and generates guidelines for implementing plant systems. The e-manufacturing strategy takes the e-business and manufacturing strategies and creates a roadmap for system development and implementation in the plant."

Another definition by Koç et al. [2]: 
"E-manufacturing is a system methodology that enables the manufacturing operations to successfully integrate with the functional objectives of an enterprise through the use of Internet, tether-free (i.e., wireless, web, etc.) and predictive technologies."

E-manufacturing, may thus, be defined as the manufacturing environment wherein all inputs (men, material, machine, money, information) are processed for transforming into customer desired output through the deployment of distributed, flexible, open, reconfigurable, scalable, extendable communication, and data management systems.

The developments in manufacturing technology have been very well depicted in Figure 1.

\section{Enablers of E-Manufacturing}

Manufacturers can achieve the promise of e-manufacturing through the enablers that drive customer oriented build-toorder processes and nonstop operations.

Twelve key enablers have been identified for manufacturers to rapidly reap the benefits of e-manufacturing as discussed below.

2.1. Advanced Manufacturing Technology. Manufacturing has been defined by Lin and Nagalingam [4] and Wu [5]: "the organized process whereby products are made or created by various production activities from raw material".

Technology has been defined by Winner [6] from three dimensions: apparatus, referring to the equipment itself; technique, referring to the skills and knowledge necessary to use the equipment; and organization, referring to systems and structures of control and coordination.

Advanced word only reflects the phase of manufacturing. Thus, the word "Advanced Manufacturing Technology" came which only reflects the current phase of manufacturing technology.

Zammuto and O'Connor [7] defined AMT as a broad spectrum of computer-controlled automated process technologies. Beaumont et al. [8] described AMT more specifically as a group of computer-based technologies, including computer-aided design (CAD), computer numerical control (CNC) machines, direct numerical control (DNC) machines, robotics (RO), flexible manufacturing system (FMS), automated storage and retrieval system (AS/RS), automated material handling systems (AMHS), automated guided vehicles (AGV), bar coding (BC), rapid prototyping (RP), material requirement planning (MRP), statistical process control (SPC), manufacturing resource planning (MRP II), enterprise resource planning (ERP), activity-based costing $(\mathrm{ABC})$, and office automation (OA).

As such Advanced Manufacturing Technology can be viewed as encompassing the computer and numerical-based apparatus (software and hardware) designed to accomplish or support manufacturing tasks. This definition excludes "managerial technologies" but may include, for instance, information networks for shop-floor data.
2.2. Web-Enabled Technologies and Services. E-manufacturing means giving the organization agility to react quickly to changes in the market, technology and customers by operating as a virtual enterprise. To exist as a virtual enterprise web-enabled technologies and services are required to integrate and synchronize information gathered based on inputs from customers, markets, and technology. Webenabled decision-making portal shall perform dynamic optimization and synchronization based on the gathered information. Being one of the most important enablers of emanufacturing, it should be based on a standard yet flexible protocol to assist manufacturing platforms.

Jin et al. [9] has discussed about web-enabled technologies and services in Networked Virtual Environments (NetVEs) which provide an insightful, intuitive, and interactive system and allows effective communication among multiple users. The system allows engineers and designers to visualize, explore, manipulate, and interact with manufacturing applications in Net-VEs. Additionally, the industrial users can easily apply and share the manufacturing 3D data through web. By reducing costs and cycle time of product development, such an e-manufacturing system will speed up the major activities of manufacturing engineering including simulating manufacturing processes; optimizing assembly lines and workshops design; integrating labor and equipment, and hence, producing better quality products in a shorter time at more competitive price.

2.3. Stakeholder Interface and Feedback Mechanism. All stakeholders of a particular e-manufacturing environment should have an interface to interact with the system. The participation of stakeholders brings in the responsibility to ensure the correctness of input data and streamline the flow of information. The feedback mechanism thereby corrects any flaw in real-time by equating the current process with the correct process. Particularly, a Customer Relationship Management (CRM) package may be used for the purpose. In this age of the global market, with worldwide customers and remote offices, a web based software solution can help you manage your customers without any constraints of location or time.

As discussed by Lee et al. [10], an e-manufacturing strategy provides direct information exchanges between manufacturing and Customer Relationship Management (CRM) systems and supply chain management systems. It gives a complimentary set of process optimization methodologies for designing, operating, maintaining, or synchronizing the manufacturing operation using real-time information processing through stakeholders participation.

2.4. Quality Tools and Techniques. The efficient and consistent operation of plant throughout the enterprise is essential to attain high productivity which has always been a focus in manufacturing. As manufacturers consolidate through acquisitions and so have new facilities to operate worldwide, they must also learn how to make products with consistent quality and efficiency at each manufacturing location. This is where initiatives like lean manufacturing 


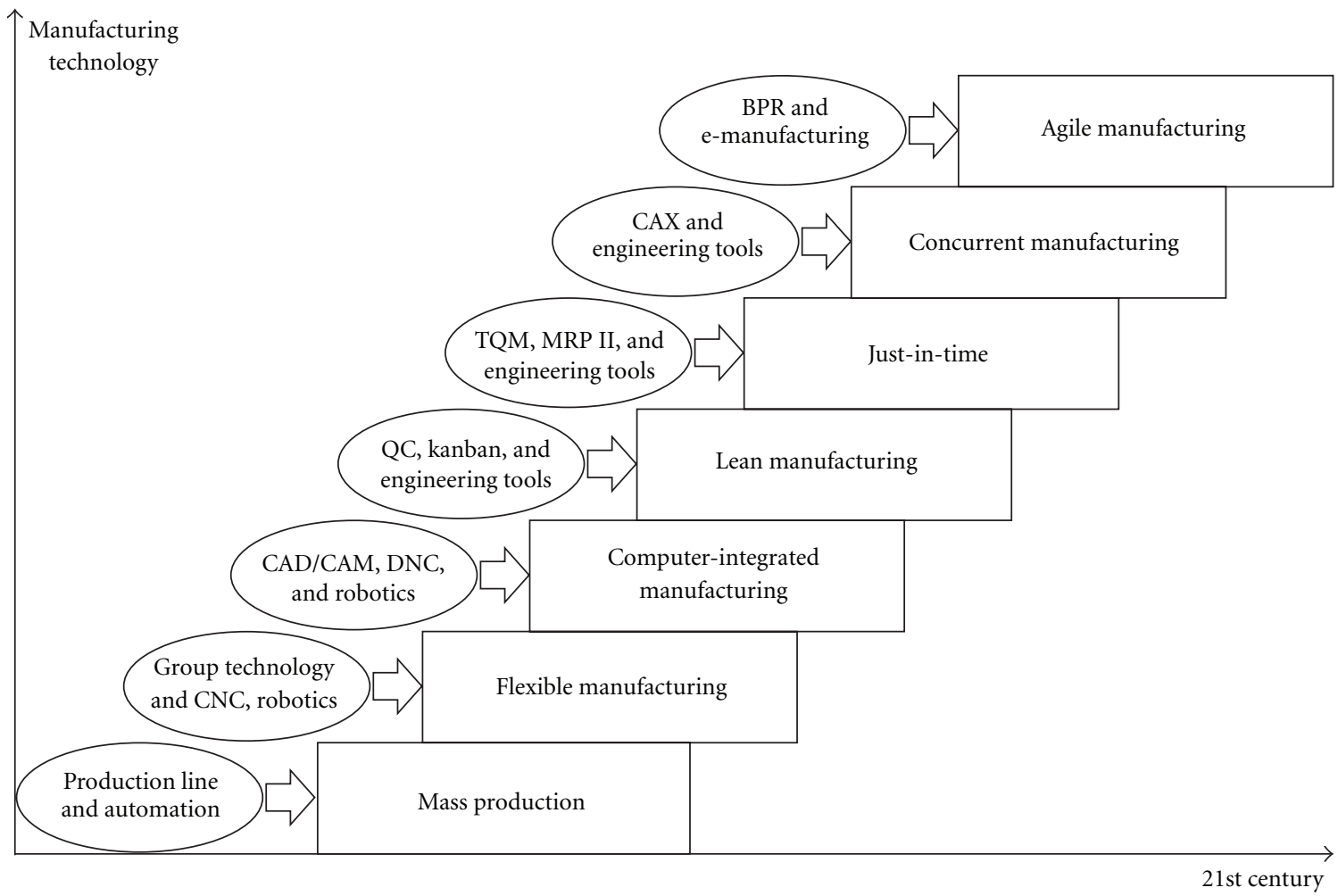

Figure 1: Development in manufacturing technology as adapted from Cheng and Bateman [3].

drive out waste, achieving nonstop operations for maximum efficiency and output, and where techniques like Six Sigma reduce variability in processes to ensure peak quality. Such quality tools and techniques need to be infused all along the e-manufacturing system to attain error-free working environment and thereby a quality product.

For achieving quality in e-manufacturing system, new standards need to be further identified and developed for the functional elements of the enabling tools for a manufacturing pant. These efforts should leverage the existing standard activities (i.e., IEEE 802.xx standard committees, MIMOSA, etc.) as discussed by Lee [11].

Rockwell Automation [12] published a white paper stating four competencies (design, operate, maintain, and synchronize) that are required for any manufacturer to be a world class manufacturing company.

2.5. Data Management System. Data management system basically includes mainframes which gather data from various machines and processes using internet and networking for seamless data flow. Since massive raw data is not useful unless it is reduced and transformed into information and knowledge for responsive actions, data mining tools for data reduction, representation and prediction adopted for plant floor data need to be developed. Corrective and proactive maintenance has to be implemented for the success of emanufacturing.

As rightly depicted by Shivanand et al. [13], the large amounts of raw data collected during a manufacturing proc- ess are rendered useless, unless the data is gathered and transformed into some useful information which may be used to monitor a system.

2.6. Network Security. As the success of e-manufacturing depends on the seamless data flow across different agents of manufacturing, the security of network carrying this essential data becomes utmost critical for the working of emanufacturing system. No compromise may be allowed on this front as any kind of interference with data may result in corrupt data being carried thereby resulting in wrong interpretation. The network has to be secured from any kind of virus or worm attack. The data which is vulnerable of being captured on internet while being transferred should be encrypted first and then transferred to the desired location.

Data/information security and vulnerability issues at the machine/product level need to be identified and corrected as pointed by Koç et al. [14].

2.7. Automation. Automation is the use of control systems and information technologies to reduce the need for human work in the production of goods and services. Automated manufacturing refers to the application of automation to produce things in the factory way. Most of the advantages of the automation technology have its influence in the manufacture processes.

The main advantage of the automated manufacturing are: higher consistency and quality, reducing the lead times, simplification of production, reducing handling, 
improving work flow and increasing the morale of workers when a good implementation of the automation is made. Modern, information-enabled automation architecture with associated integration management services helps in eliminating human-based errors.

The manufacturing enterprise is intensively deploying a host of hardware/software automation/information technologies in order to face the changing societal environment pulled by the increasing customization of both goods and services as desired by customers and discussed by Morel et al. [15].

Pereira and Carro [16] discusses about advances in microelectronics and software allowing embedded systems to be composed of a large set of processing elements, and the trend is towards significant enhanced functionality, complexity, and scalability, since those systems are increasingly being connected by wired and wireless networks to create large scale distributed real-time embedded systems (DRES). Such embedded computing and information technologies have become at the same time an enabler for future manufacturing enterprises as well as a transformer of organizations and markets.

2.8. Maintenance. By using strategies that are predictive not just preventative, maintenance is seen as an opportunity to prevent unnecessary downtime, increase plant availability, and improve productivity. The efficient management of all company assets: materials, processes, and employees can be a part of globally networked monitoring systems to ensure nonstop operations and optimum asset productivity. Without such a solid, efficient foundation, it is not possible to achieve the twin goals of growth and profitability simultaneously. For the purpose a web-based software package may be used.

A CMMS software package maintains a computer database of information about an organization's maintenance operations, that is, CMMIS: computerized maintenance management information system. This information is intended to help maintenance workers do their jobs more effectively and to help management make informed decisions possibly leading to better allocation of resources. CMMS data may also be used to verify regulatory compliance.

E-Maintenance strategy should be adopted to integrate and synchronize the various maintenance and reliability applications to gather and deliver asset information where it is needed, when it is needed. Interconnectivity of the islands of maintenance and reliability information is embodied in E-Maintenance as mentioned by Shivanand et al. [13].

2.9. Supply Chain. Tools, e-fulfillment, and e-procurement solutions - direct transfer of customer order details to manufacturing personnel and equipment, configuration options, and close electronic connections to suppliers and partners to optimize the inbound supply chain in the face of changing demand. The integration of manufacturing operations into the greater supply chain, both upstream and downstream will facilitate proper synchronization. Competence in this area is best achieved after the other three are in place as discussed in Koç and Lee [17]. Only then is the plant truly ready to be fully coupled into an e-commerce-driven supply chain (see Figure 2).

The importance of supply chain in an e-manufacturing system may also be gauged from the definition of e-manufacturing, "E-manufacturing is the vertical (business) and horizontal (supply-chain) integration of systems to ensure the correct dissemination of information throughout the value-chain of a business, making use of appropriate technology like the internet to ensure that real-time accurate information is available at all decision points throughout an organization and supply chain.” As enumerated by Greeff et al. [18].

Web-based supply chain management (SCM) software may be integrated with e-manufacturing system for optimum productivity.

2.10. Interoperability of Software Systems. To achieve the goal of integrating information technology with manufacturing systems, the information must flow seamlessly from location to location without loss or corruption of data. The criticality further increases with increasing complexity of the type of data to be exchanged as more and more value-creating processes has to be inbuilt. As explained in NACFAM [19], the ability to achieve the desired levels of flexibility, efficiency, and responsiveness to exploit the full potential of integration is yet to be realized despite the advances in information and communications technologies. The software systems used by different companies need to follow a common standard of communicating with each other in such a way to eliminate the possibility of any type of information or data loss.

2.11. Synchronization. Seamless integration of all tools, techniques, and processes from shop floor to top floor is required to provide a basis for successful e-business. As discussed by Koç and Lee [17] synchronization of all integral tools, techniques and processes of e-business, e-manufacturing and e-maintenance needs to be addressed as shown in Figure 3.

2.12. Educate and Train to Bring Awareness among Stakeholders. The success of e-manufacturing will ultimately depend on how well all stakeholders understand and become an integral part of it. For the purpose, it is necessitated to educate and train each stakeholder for all enabling tools and techniques. They must know their participative responsibilities to optimize the performance of e-manufacturing system.

e-Manufacturing is a transformation system that enables the manufacturing operations to achieve predictive nearzero-downtime performance as well as to synchronize with the business systems through the use of web-enabled and tether-free (i.e., wireless, web, etc.) infotronics technologies. It integrates information and decision-making among data flow (of machine/process level), information flow (of factory and supply system level), and cash flow (of business system level) as discussed in koç and lee [17]. 


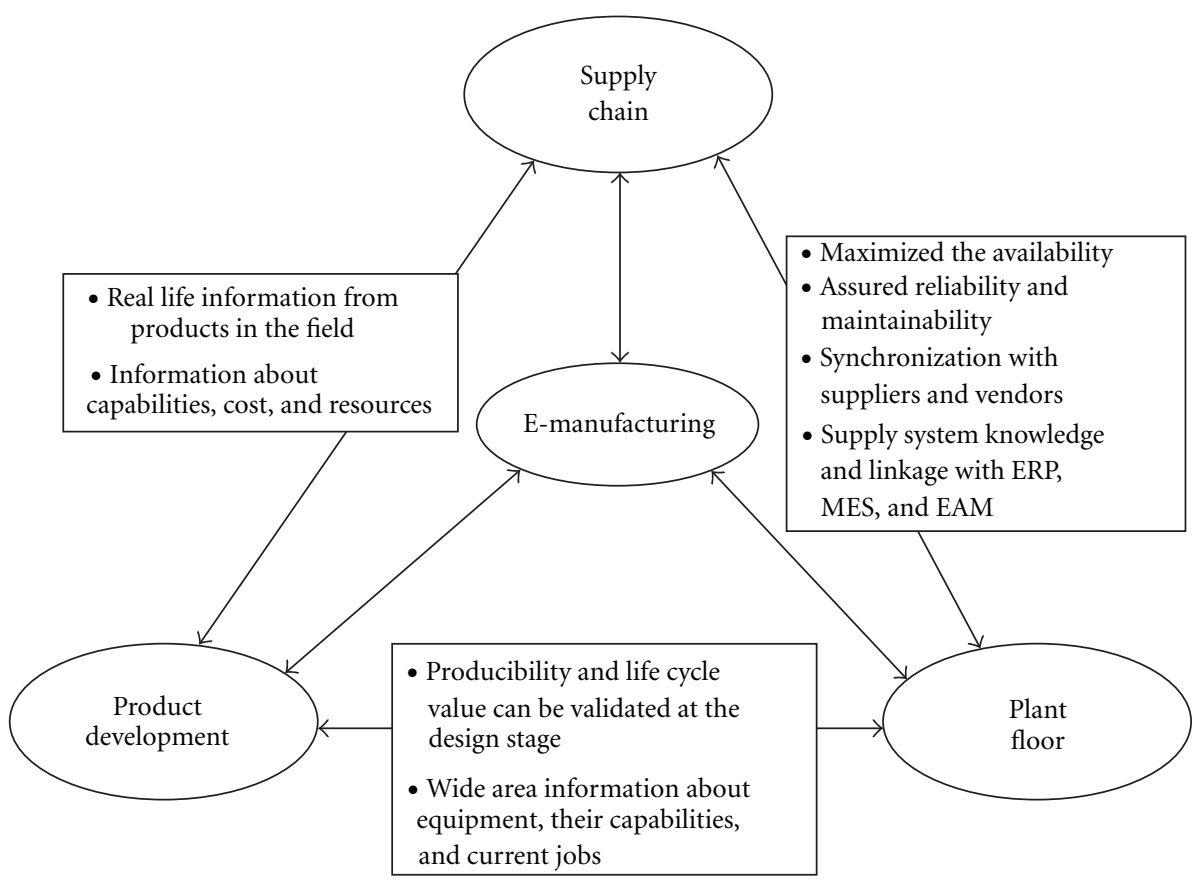

Figure 2: The transformation of e-Manufacturing for unmet needs in SCM as depicted in Koç and lee [17].

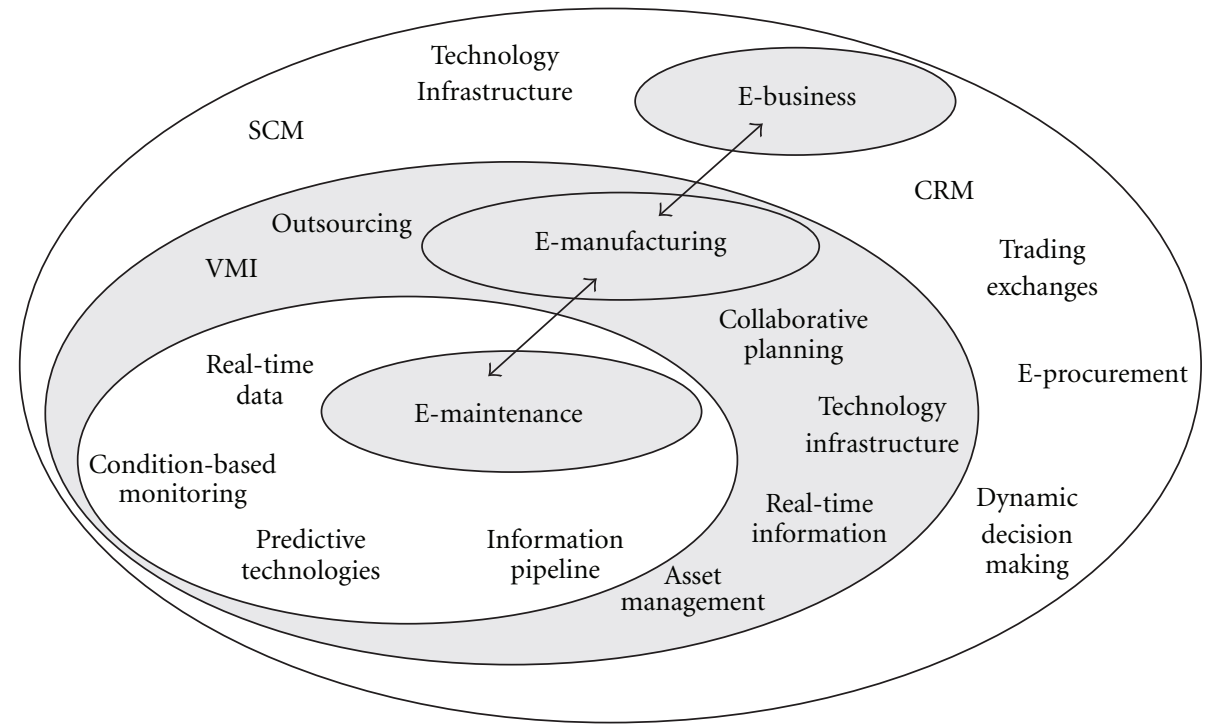

FIgURE 3: Integration of e-manufacturing with e-business and e-maintenance as depicted in Koç and Lee [17].

\section{Conclusion}

The need for e-manufacturing may be summarized as methodologies and services for increasing overall asset utilization while minimizing unplanned maintenance and unexpected downtime.

E-manufacturing is more of philosophical nature than a concrete roadmap. The degree of focus on each enabler will vary according to a particular manufacturing environment. As such it becomes essential to prepare a guideline towards implementation of e-manufacturing.

Guidelines towards implementation of e-manufacturing:
(1) Constitute a team of experts from various departments and functions within the organization. Experts may also be called from outside of the company wherever needed.

(2) The experts should meet to draw the company's roadmap for e-manufacturing. It must be ensured that each section of the organization has a vision for success based on enablers of e-manufacturing. The common and specialized benefits must be clearly outlined. A framework needs to be developed with all stakeholders' action outlined in a timely manner. 
(3) The internet should be an inherent part of the manufacturing system, and all human resource of the company must adopt it.

(4) Engineers along with first line workers being an integral part of the shop-floor decision-making process, their experience and vision shall be invaluable in seamless integration of shop floor with emanufacturing.

(5) The head of the company should also be the head of e-manufacturing system. Any strategy towards benefit of the company must have e-manufacturing as a key element of that broader strategy.

(6) All stages of the roadmap should be measured towards its success and failure. Measurable targets should be placed to determine the real savings and efficiencies from a transparent company.

(7) Existing foundations of the company should be used to build upon for incremental successes along the way. An e-manufacturing strategy will help the organization embrace information transparency, fostering operational excellence while cutting down on wastes.

(8) Evaluate and streamline the existing processes with customers, suppliers, distributors, and others to optimize their effectiveness in e-manufacturing system.

(9) Educate and train all stakeholders in pursuing goal of increasing efficiency on every front and harnessing all possible benefits from e-manufacturing.

Organizations are now trying to create a wonderful experience for their customers and are focusing more on the experience that their customer has which stems from a deep desire on the customer's part to have a good relationship with the company. This will ensure a better managed emanufacturing system within e-business.

\section{References}

[1] "An e-manufacturing strategy needs to be developed from the manufacturing strategy," AMR Research, Inc, August 2000.

[2] M. Koç, J. Ni, and J. Lee, "Introduction of e-manufacturing," in Proceeding of the International Conference on Frontiers on Design and Manufacturing, pp. 43-47, Dalian, China, July 2002.

[3] K. Cheng and R. J. Bateman, "E-manufacturing: characteristics, applications and potentials," Progress in Natural Science, vol. 18, pp. 1323-1328, 2008.

[4] G. Lin and S. Nagalingam, CIM Justification and Optimisation, Taylor and Francis, London, UK, 1st edition, 2000.

[5] B. Wu, Manufacturing Systems Design and Analysis, Chapman \& Hall, London, UK, 2nd edition, 1994.

[6] L. Winner, Autonomous Technology, MIT Press, Cambridge, Mass, USA, 1977.

[7] R. Zammuto and E. O’Connor, “Gaining advanced manufacturing technologies' benefits: the roles of organization design and culture," Academy of Management Review, vol. 17, pp. 701-728, 1992.

[8] N. Beaumont, R. Schroder, and A. Sohal, "Do foreign-owned firms manage advanced manufacturing technology better,"
International Journal of Operations \& Production Management, vol. 22, no. 7, pp. 759-771, 2002.

[9] L. Jin, I. A. Oraifige, P. M. Lister et al., "E-manufacturing in networked virtual environments," in Proceedings of the IEEE International Conference on Systems, Man and Cybernetics, vol. 3, pp. 1845-1849, October 2001.

[10] J. Lee, A. Ali, and M. Koç, "E-manufacturing-its elements and impact," in Proceedings of the Annual Institute of Industrial Engineering Conference, vol. 23, Dallas, Tex, USA, May 2001.

[11] J. Lee, "E-manufacturing-fundamental, tools, and transformation," Robotics and Computer-Integrated Manufacturing, vol. 19, no. 6, pp. 501-507, 2003.

[12] "Rockwell Automation E-manufacturing Industry Road Map, ," http://www.rockwellautomation.com/.

[13] H. K. Shivanand, N. V. Nanjundaradhya, and P. Kammar, "E-manufacturing a technology review," in Proceedings of the World Congress on Engineering, vol. 2, London, UK, July 2008.

[14] M. Koç, J. Ni, J. Lee et al., "Introduction of e-manufacturing," in Proceedings of the International Conference on Frontiers on Design and Manufacturing, pp. 1-10, July 2005.

[15] G. Morel, P. Valckenaers, J. M. Faure et al., "Manufacturing plant control: challenges and open issues," in Proceedings of the 16th IFAC Triennial World Congress, 2005.

[16] C. E. Pereira and L. Carro, "Distributed real-time embedded systems: recent advances, future trends and their impact on manufacturing plant control," Annual Reviews in Control, vol. 31, no. 1, pp. 81-92, 2007.

[17] M. Koç and J. Lee, "E-manufacturing-fundamentals, requirements and expected impacts," International Journal of Advanced Manufacturing Systems, vol. 6, no. 1, pp. 29-46, 2003.

[18] G. Greeff, R. Ghoshal, and S. Mackay, Practical E-Manufacturing and Supply Chain Management, chapter 1, Elsevier, 2004.

[19] NACFAM, Exploiting E-Manufacturing: Interoperability of Software Systems Used By U.S. Manufacturers, National Coalition for Advanced Manufacturing, Washington, DC, USA, 2001. 

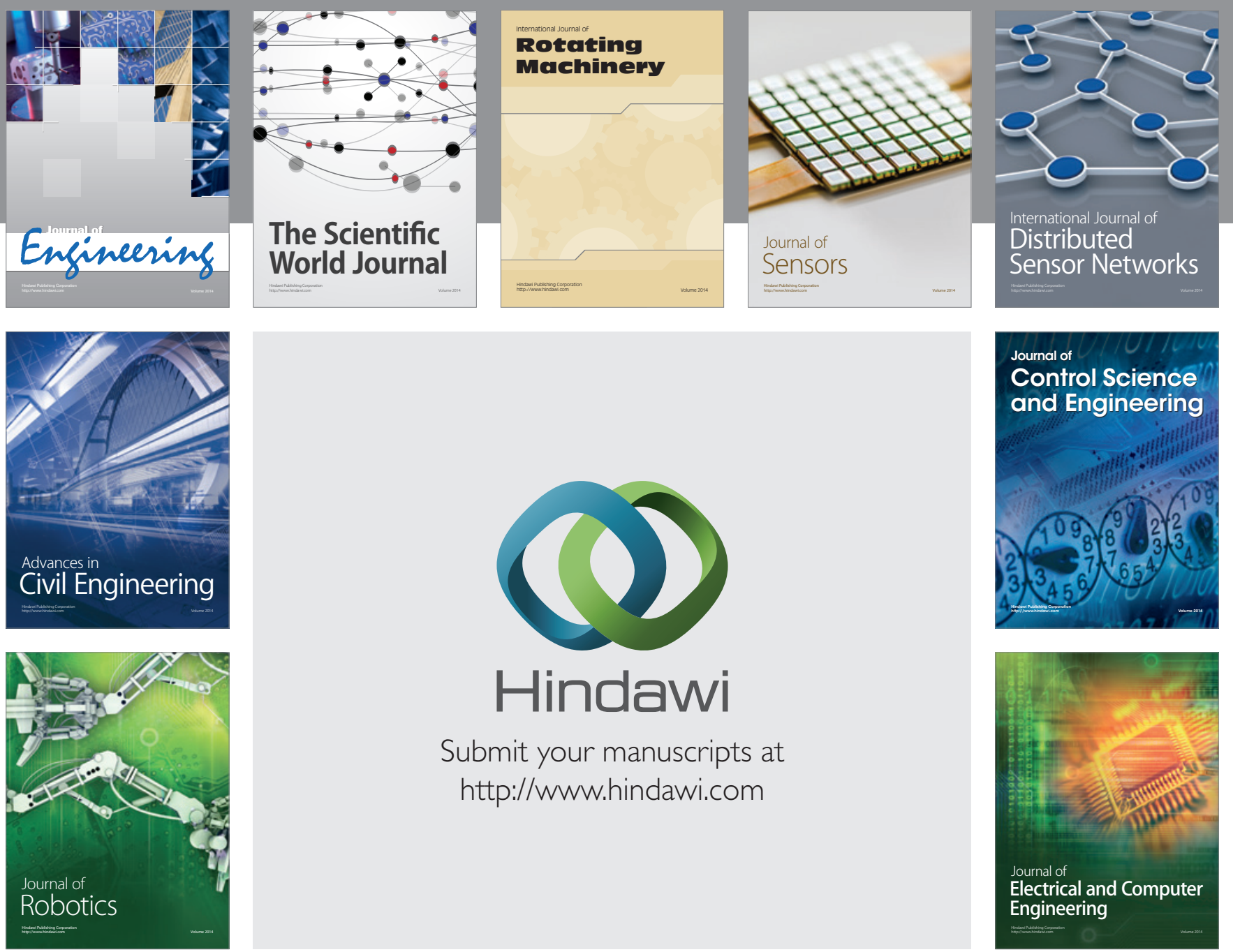

Submit your manuscripts at

http://www.hindawi.com
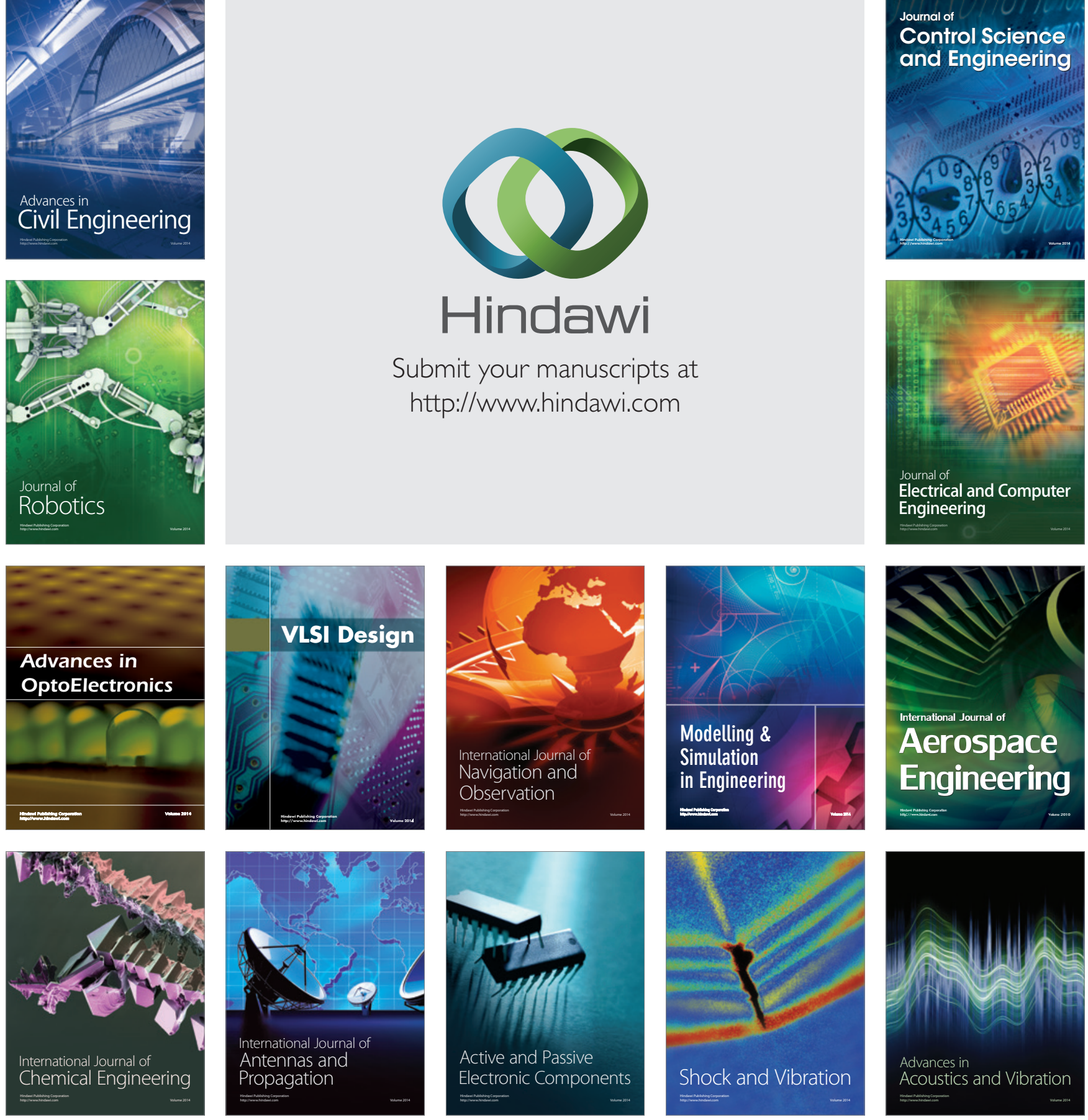